\title{
Reconnoitering Teachers' Vocabulary Teaching Strategies: The Case of Grade Nine Teachers' in Kokebe Tsibah Secondary and Preparatory School, Addis Ababa
}

\author{
Melaku Bayu Workie \\ Debre Tabor University, Faculty of Social Sciences and Humanities, Department of English Language and \\ Literature, Debre Tabor, Ethiopia
}

\begin{abstract}
The main objective of this study was to investigate vocabulary teaching strategies used by grade nine teachers in Kokebe Tsibah Secondary and Preparatory School in Addis Ababa. The study used a descriptive survey method that involves quantitative and qualitative methods. Questionnaire, classroom observation and interview were used to gather the necessary data for the study. Thirteen English teachers from both grade nine and ten were selected through availability sampling for the questionnaire. Four of the teachers who were only teaching grade nine students were observed four times in their actual classroom and interviewed. And data were collected from 96 randomly chosen grade nine students through questionnaire. Eight students were interviewed. Thus, descriptive statistics such as frequencies, percentages and mean were employed in analyzing the quantitative data. The qualitative data were analyzed and reported. The overall findings of the study showed that teachers did not use the various vocabulary teaching strategies in the English classes. Teachers most frequently used definition, antonym and synonym; contextualization was occasionally used. Based on the findings, it is recommended that creating meaningful vocabulary teaching opportunities through various vocabulary teaching strategies are supposed to be practiced widely. Further studies were recommended.
\end{abstract}

Keywords: Reconnoitering, Vocabulary, Strategy, Teaching, Investigate, Technique

DOI: $10.7176 /$ JAAS/60-04

Publication date: January $31^{\text {st }} 2020$

\section{Introduction}

\subsection{Background of the Study}

The history of second language teaching can be traced back to Romans. During this period and afterwards different approaches to language teaching, each with different perspectives on vocabulary teaching, have been introduced. Some times, vocabulary had a good place in language teaching methodologies, other times it was entirely ignored (Allen, 1983; Tylor, 1991 and Schmitt, 2000).

The method of language teaching has been changing from grammar translation to direct method and then to communicative approach. However, it was only during the communicative approach that the prominent role of vocabulary knowledge in second or foreign language learning and teaching has been recognized. The current popular communicative approach to language teaching has emphasized meaningful interactive activities over form. It is also recognized that the vocabulary learning techniques that students use have greater impact on the success of their vocabulary learning (Hatch and Brown, 1995).

The teaching and learning of English as a foreign language in Ethiopian educational settings can be associated with the introduction of modern education in the country. In Ethiopia, modern education was introduced at the turn of the $20^{\text {th }}$ century (Diribsa, et al., 1999). The history of foreign language learning and teaching in Ethiopia, therefore, is traced back to the early $20^{\text {th }}$ century.

English is a language that learners learn in all levels of Ethiopian schools, colleges and universities. It gives the impression that English is delivered as a distinguished discipline in all levels of schools, and it is a medium of instruction for all school subjects other than the local language (Abebe, 1997).

Currently, a greater consideration is being given to English language teachers and students to make them proficient enough in the application and use of the micro-skills and macro-skills. Particular consideration is given to the enhancement of students' vocabulary since words play an important role in expressing feelings, emotions and ideas to others during communication. This means that without the mediation of vocabulary, no amount of grammatical or other types of linguistic knowledge can be thought of in second language communication (Miller, 2000).

It is important for the teacher to employ effective and dynamic teaching techniques/strategies that will empower the students to master the required tasks. Stahl (1999) found that vocabulary instruction directly improves comprehension. He points out that as the difficulty of words in a text increases, understanding of the text decreases. Therefore, it is critical for students to have a deep understanding of vocabulary to understand new concepts. Vocabulary is also used to communicate to the world what we know. Individuals who can express themselves precisely with appropriate language are more likely to make a positive impression on their employers, colleagues 
and clients.

McCarthy (1990) declares that knowledge of vocabulary enables us to communicate our needs. This increases our chances of getting our needs fulfilled. Knowledge of words also enables us to understand the needs of others. Moreover, vocabulary is positively related to higher status occupations. It is essential to academic, social and professional success. The teacher's role in ensuring this success is critical. However, EFL teachers still have problems in practicing different vocabulary teaching strategies.

\subsection{Statement of the Problem}

Vocabulary learning is one of the major obstacles confronting second language learners. Students in all levels of education have a difficulty of expressing their ideas, desires and feelings as clearly as they would like to. Many did not understand or grasp the idea transmitted to them (Al-knfasm, 1988). This is because, for many years, vocabulary has been the victim of discrimination by researchers who claimed grammar to be a more significant issue in the language development process. In addition, teachers still fail to use diversified ways of teaching vocabulary. In the past, because of the effect of structuralism, which did not regard vocabulary as an area to focus on, the issue of vocabulary remained ignored (Carter \&.McCarthy, 1988). But, today, the importance of vocabulary for language teaching is admitted by all second language theorists and practitioners. Although it was believed that vocabulary could be taught only in isolated word lists for a long time, nowadays there are lots of ways to teach vocabulary such as contextualization, sense relationships, networking, collocation, etc. (Schmitt 2000, Coady \& Huckin, 2000).

Moreover, lexical competence is currently accredited to be a core component of communicative competence by many vocabulary specialists, which provides much of the basis for how well learners speak, listen, read and write (Richards \& Renandya, 2002). The movement toward effective methodologies for teaching vocabulary has emerged and researchers and language teachers have also suggested many strategies/techniques for vocabulary learning and teaching, which are dependent on the efforts of each learner (Cohen \& Macaro, 2007).

Much has been said about the discrimination of vocabulary teaching in EFL classes. There are several researches conducted in the areas of vocabulary teaching without considering their effect on teaching language (Schmitt, 2000). But little attention is given to studying the extent to which English language teachers employ different techniques in vocabulary teaching in schools. Therefore, exploring teachers' vocabulary teaching techniques used in Kokebe Tsibah Secondary and Preparatory School is very important.

There are a few local studies on vocabulary teaching strategies in the Ethiopian context. In line with this, Dessie (1988), Sara (1989), Tesfaye (1990) and Alemu (1994) studied on vocabulary teaching. Though these researchers attempted to look into vocabulary teaching in EFL classrooms, none of them looked at the extent to which English language teachers employ different techniques in vocabulary teaching at high school level. And to the knowledge of the researcher there has not been any research that explored teachers' vocabulary teaching techniques at Kokebe Tsibah Secondary and Preparatory School. For instance, Dessie (1988) and Tesfaye (1990) evaluated the effectiveness of vocabulary teaching methods. And Alemu (1994) studied teachers' attitude towards awareness raising approach to vocabulary teaching.

Accordingly, the current study is basically different from the above studies. It focuses on the strategies/techniques of vocabulary teaching and to what extent teachers get involved their students in every opportunity through which they can be exposed to different vocabulary learning- teaching techniques. At Kokebe Tsibah Secondary and Preparatory School, vocabulary teaching has been paid less attention than it should have been, as compared to major language skills which are taught. This could contribute to this school students' vocabulary deficiency.

Therefore, the present researcher understood that vocabulary teaching through different strategies is one of the most important components of any language class. This is because techniques enable learners' to probe and grasp the essential concepts of different vocabularies that they may face.

Understanding the problem of vocabulary teaching at Kokebe Tsibah Secondary and Preparatory School and the existing research gap, the researcher is initiated to conduct a research on investigating grade nine teachers' vocabulary teaching strategies.

\subsection{Research Questions}

The study attempts to answer the following research questions in particular.

1. What strategies do teachers employ to teach vocabulary?

2. How often are the vocabulary teaching strategies used by teachers?

1.4 Objectives of the Study

1.4.1 General Objective

The main objective of this study is to investigate vocabulary teaching strategies used by grade nine teachers' in Kokebe Tsibah Secondary and Preparatory School, Addis Ababa. 


\subsubsection{Specific Objectives}

The specific objectives of this study are to:

\# identify the strategies teachers employ to teach vocabulary.

* examine how often the vocabulary teaching strategies are employed by teachers.

\section{Materials and Method}

\subsection{Research Design}

This is a descriptive study. Qualitative and quantitative approaches were employed. These approaches were chosen because they could provide in-depth information concerning grade nine teachers' vocabulary teaching techniques. Hence, both qualitative and quantitative data were collected, analyzed and interpreted in the study. Quantitative data were used through questionnaire, and qualitative data were used through interview and classroom observation.

\subsection{Research Site}

This study was carried out in grade nine in Kokebe Tsibah Secondary and Preparatory school in Addis Ababa. The school was chosen because of its proximity to the researcher.

\subsection{Participants}

The target populations of this study were English teachers, who were teaching both grade nine and ten students and grade nine students of Kokebe Tsibah Secondary and Preparatory School in Addis Ababa. Grade nine students were selected for the study since the researcher had personally witnessed the problem under investigation at this level.

\subsection{Sample Size and Sampling Technique}

Comprehensive sampling was used to select the teachers to participate in the study. This means that all grade nine and ten English teachers took part in the study. They were 13 teachers ( 7 males and 6 females). Four of the teachers were teaching only grade nine students while nine of them were teaching both grades nine and ten students. Simple random sampling technique was applied to choose students. There were eight sections, and there were 40 students in each section. So, three hundred and twenty students were taken as total population for the study. The researcher took $30 \%$ of the students, that is, 96 . The participants were randomly selected from the total population of students through simple random sampling technique. Lottery method was used to select the participants based on attendance sheet. Random sampling, according to Bailey (1994), gives chances for everyone to be a member of the sample. Out of 96 students selected, eight were randomly chosen for the interview. All English teachers were involved in the questionnaire. The four teachers who were teaching only grade nine students were used as subjects for both classroom observation and interview.

\subsection{Data Gathering Instruments}

To obtain adequate information for the study, data collection tools were employed, notably, questionnaire, classroom observation and interview. The instruments were selected because of their suitability for gathering important data for the study. Multiple data gathering tools were important for triangulation to ensure the validity of the data collected.

In order to gather relevant data for the study, questionnaire with appropriate items were designed and administered to both teachers and students. The questionnaire composed of 22 Likert-type closed-ended items were given to the participants. To get information about the techniques of vocabulary teaching, teachers and students were required to provide the frequency with five-point Likert-scale that constitute always, usually, sometimes, rarely and never. The scale values ranged from 5 to 1 , respectively.

All grade nine English teachers (4) were observed during their vocabulary lesson periods. Each teacher was observed four times using a structured observation checklist. The observation checklist incorporated items which are all concerned with vocabulary lesson presentations at different times.

There were seven interview questions for teacher participants and five interview questions for students. Four of the teachers and eight randomly selected students were interviewed. The interview was deliberately done to maximize the reliability of the data obtained through questionnaire. This is also believed to help the researcher to cross-check the respondents' response to the questionnaire.

\subsection{Data Collection Procedure}

The data collection sessions were arranged according to the times suggested by the school principals' and the willingness of the participants. Collecting the data took over two months. First, classroom observation was made. This was followed by questionnaire and interview.

Therefore, concerning classroom observation, the researcher prepared a checklist. The classroom observation was made based on the checklist containing different vocabulary teaching techniques. Questionnaire was 
distributed to 96 students in the presence of the researcher at a normal class time and all of them were returned. And, then, another set of questionnaire was distributed to 13 English teachers. This means that there were 13 teachers. Then, interviews with both teachers and students were conducted.

\subsection{Method of Data Analysis}

The collected data were analyzed, interpreted and discussed accordingly. Quantitative data which were collected from the respondents were analyzed using Statistical Package for the Social Science students (SPSS 16.0) software analysis. The quantitative data collected through close-ended questions were entered into the computer and statistically described in terms of mean, percentage and frequency. Finally, the qualitative data obtained through interview were analyzed thematically.

\section{Results and Discussion}

\subsection{Teachers' Responses to Items Related to their Classroom Practices of Vocabulary Teaching Strategies}

Table 3.1.1: Frequency, percentage and mean of responses to items related to classroom practices of vocabulary teaching strategies

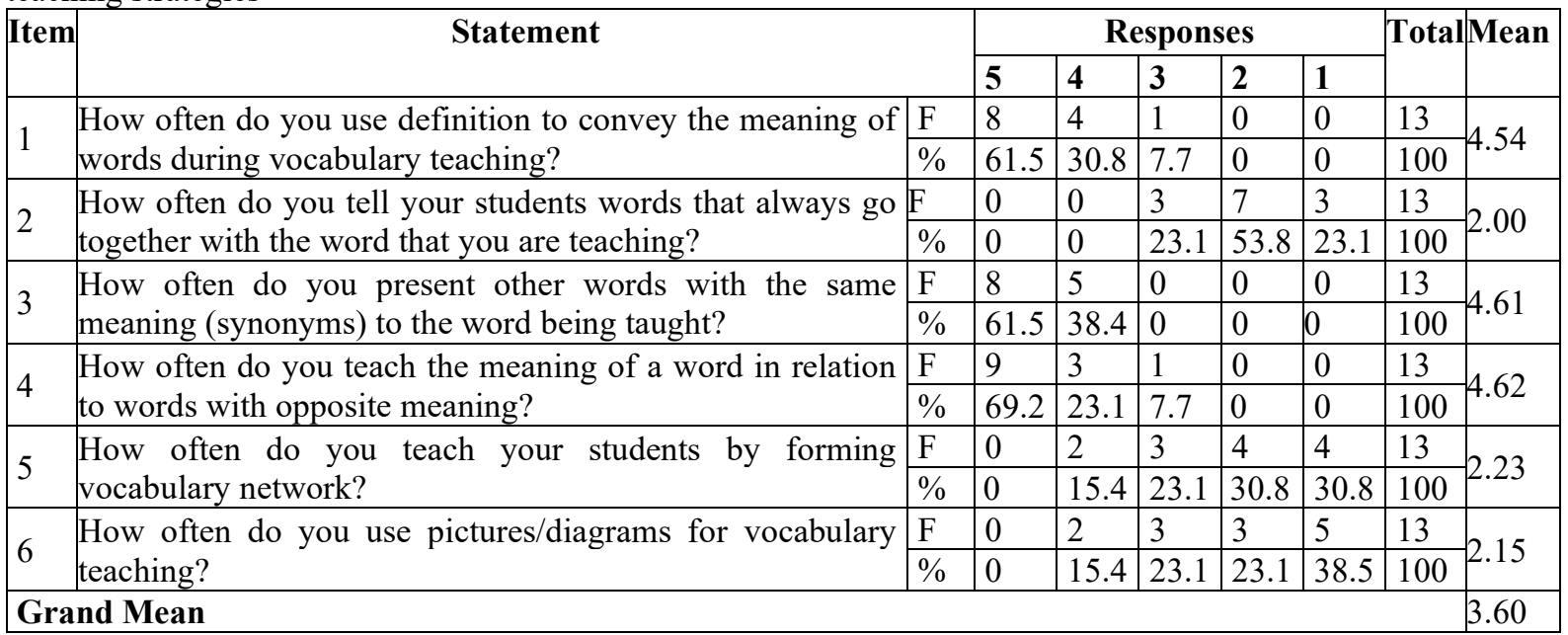

Key: $\mathbf{5}$ =Always, $\mathbf{4}=$ Usually, $\mathbf{3}=$ Sometimes, $\mathbf{2}=$ Rarely, $\mathbf{1}=$ Never, $\mathbf{F}=$ Frequency, $\mathbf{\%}=$ =Percent

As can be seen from the table above (see item number 1$)$, slightly over a half of the respondents $(62 \%)$ replied that they always used definition to convey the meaning of new words during vocabulary teaching. Another $31 \%$ of the respondents answered that they usually used definition in their vocabulary teaching. And $8 \%$ of the participants sometimes used definition to express the meaning of new words in their vocabulary teaching.

In reply to item number $2,23 \%$ of the respondents replied that they sometimes used collocation in their vocabulary teaching. $54 \%$ of the teachers responded that collocation was rarely used in the classroom. But, $23 \%$ of the teachers never used collocation in their vocabulary teaching. Collocations did not get enough attention. But, according to Nattinger (1988), with the help of collocations, the learner keeps the words in memory and can easily infer the meaning from the context. Therefore, collocations should be given a prime consideration in vocabulary teaching.

As regards item number $3,62 \%$ of the participants responded that they always used synonyms in the actual classroom. And $38 \%$ of the respondents replied that they usually employed synonyms in their vocabulary teaching. In item number $4,69 \%$ of the teachers always used antonyms in their vocabulary teaching. $23 \%$ the respondents replied that they usually used antonyms in the actual classroom. And also $8 \%$ of the participants sometimes practiced antonyms in their vocabulary lesson. This means that synonyms and antonyms were the most frequently used techniques.

The reply to item number 5 revealed that $15 \%$ and $23 \%$ of the teachers usually and sometimes practiced vocabulary teaching by forming vocabulary network, respectively. As opposed to this, $31 \%$ of the participants responded that they rarely taught their students vocabulary by forming vocabulary network. And the other $31 \%$ of the teachers never taught their students vocabulary through vocabulary network. Item number 6 showed that $15 \%$ and $23 \%$ of the teachers usually and sometimes used pictures or diagrams in their vocabulary teaching, respectively. The other $23 \%$ of the respondents rarely practiced vocabulary through pictures or diagrams. However, $39 \%$ of the participants replied that they never used pictures and diagrams in their vocabulary teaching.

Based on the above facts one can conclude that definition, synonym and antonym were the most frequently used strategies of vocabulary teaching. The result of the computed aggregate mean value is 3.60. This indicates that many of the techniques were not practiced as often as they should. 
Table 3.1.2: Frequency, percentage and mean of responses to items related to classroom practices of vocabulary teaching strategies

\begin{tabular}{|c|c|c|c|c|c|c|c|c|c|}
\hline & \multicolumn{5}{|c|}{ Responses } & \multicolumn{2}{|c|}{ Total|Mean } \\
\hline \multicolumn{3}{|c|}{ ItemStatement } & \multirow[t]{2}{*}{5} & \multirow[t]{2}{*}{4} & \multirow[t]{2}{*}{3} & \multirow[t]{2}{*}{2} & \multirow{2}{*}{1} & \multirow{2}{*}{13} & 3.46 \\
\hline \multirow{2}{*}{7} & \multirow{2}{*}{$\begin{array}{l}\text { How often do you use reading texts to teach new vocabulary } \\
\text { items? }\end{array}$} & $\mathrm{F}$ & & & & & & & \multirow{2}{*}{3.46} \\
\hline & & $\%$ & 15.4 & 23.1 & 53.8 & 7.7 & 0 & 100 & \\
\hline \multirow[b]{2}{*}{8} & \multirow{2}{*}{$\begin{array}{l}\text { In using reading texts for vocabulary teaching, how often do } \\
\text { you help your students to guess the meaning of words by } \\
\text { indicating to them useful strategies and specific clues? }\end{array}$} & $\mathrm{F}$ & 2 & 3 & 6 & 2 & 0 & 13 & \multirow[b]{2}{*}{3.46} \\
\hline & & $\%$ & 15.4 & 23.1 & 46.2 & 15.4 & 0 & 100 & \\
\hline \multirow[b]{2}{*}{9} & \multirow{2}{*}{$\begin{array}{l}\text { How often do you connect the word to many other words } \\
\text { which have meaning relationship by establishing a kind of } \\
\text { network system (word web, word map, mind map, word } \\
\text { association)? }\end{array}$} & $\mathrm{F}$ & 1 & 1 & 2 & 3 & 6 & 13 & \multirow[b]{2}{*}{2.10} \\
\hline & & $\%$ & 7.7 & 7.7 & 15.4 & 23.1 & 46.2 & 100 & \\
\hline \multirow{2}{*}{10} & \multirow{2}{*}{$\begin{array}{l}\text { How often do you use different techniques of teaching } \\
\text { vocabulary according to their suitability? }\end{array}$} & $\mathrm{F}$ & 0 & 1 & 4 & 7 & 1 & 13 & \multirow[b]{2}{*}{2.51} \\
\hline & & $\%$ & 0 & 7.7 & 30.8 & 53.8 & 7.7 & 100 & \\
\hline \multirow[b]{2}{*}{11} & \multirow{2}{*}{$\begin{array}{l}\text { After teaching words, how often do you ask your students to } \\
\text { use the words in their own sentences to check whether they } \\
\text { have learned them correctly? }\end{array}$} & $\mathrm{F}$ & 1 & 1 & 1 & 4 & 6 & 13 & \multirow[b]{2}{*}{2.00} \\
\hline & & $\%$ & 7.7 & 7.7 & .7 .7 & 30.8 & 46.2 & 100 & \\
\hline \multicolumn{3}{|c|}{ Grand Mean } & & & & & & & 2.71 \\
\hline
\end{tabular}

Key: $\mathbf{5}=$ Always, $\mathbf{4}=$ Usually, $\mathbf{3}=$ Sometimes, $\mathbf{2}=$ Rarely, $\mathbf{1}=$ Never, $\mathbf{F}=$ Frequency, $\mathbf{\%}=$ Percent

As revealed in Table 4.1.2, the response to item number 7 disclosed that $15 \%$ of the teachers always used reading texts to teach new vocabulary items. $23 \%$ of the respondents replied that they usually employed reading texts to teach new vocabulary items. But, most of $(54 \%)$ the teachers sometimes used reading texts in their vocabulary teaching. $8 \%$ of the respondents rarely practiced reading texts to teach new vocabulary items in their actual classroom. In connection to this, item number 8 reported that $15 \%$ of the respondents always taught their students to guess the meaning of new words from their context. $23 \%$ of the teachers usually practiced them. $46 \%$ of the teachers sometimes taught their students to guess the meaning of new words by indicating useful strategies and specific clues. But, $15 \%$ of the participants rarely taught their students through context. According to Nation (1990), guessing the meaning of new words from context is the best way to acquire new vocabulary items. When students consciously consider the context in which the word occurs, they are inferring the meaning. This technique is effective as students construct their own working definition for a word. This method of acquiring the meaning and the new word is best done through reading.

As regards to item number $9,8 \%$ of the teachers always used and $8 \%$ of them usually employed vocabulary network system such as word web, word map, mind map and word association. The other $15 \%$ of the respondents replied that they sometimes used vocabulary network system such as word web, word map, mind map and word association. $23 \%$ of them rarely taught through vocabulary network system. But, most of them (46\%) never practiced it in their actual classroom.

As far as practicing different techniques of vocabulary teaching according to their suitability is concerned, responses of the teachers to item number 10 indicated that $8 \%$ of the participants usually practiced them. $31 \%$ of the teachers sometimes used the techniques according to their suitability. However, most teachers $(54 \%)$ rarely practiced it. The other $8 \%$ never used varied techniques of vocabulary teaching according to their suitability. Similarly, in item $11,8 \%$ of the teachers always asked their students to use words in their own sentences to check whether they have learnt them or not. Most teachers didn't let their students communicate with their teacher or their peers in the classroom. $8 \%$ of them usually practiced it. The other $8 \%$ of the respondents responded that they sometimes asked their students to use words in their own sentences. $31 \%$ and $46 \%$ of the teachers rarely and never, respectively, used it in their actual classroom. The result of the computed aggregate mean value is 2.71 . This indicates that the techniques were not practiced as often as they should.

As far as classroom observation is concerned, almost all teachers frequented few of the techniques of vocabulary teaching, but dominantly, all of them used definition, antonyms and synonyms. A few of the teachers sometimes used contextualization as a method of teaching vocabulary. Collocation as a technique of vocabulary teaching was almost never practiced by any of the teachers. It was only practiced by $\mathrm{T}_{2}$ in the third observation. The remaining techniques like vocabulary network (word map, word web, mind map, word association), polysemy, homonym and hyponym were totally ignored in their classroom vocabulary teaching, but these techniques are suggested in the students' textbook.

Interview data obtained from the teachers showed that most of them have awareness about the importance of vocabulary teaching techniques. But, most of the teachers were not eager to use the techniques because the techniques and the activities which are provided in the textbook don't have close link to each other, that is, they are different. And the teachers are unable to adapt the activities. This has negative effect on the students' 
vocabulary learning.

The teachers' responses to the four open-ended items revealed that there were factors that hampered the practice of vocabulary teaching techniques in English classes. Almost no induction and training was given to teachers concerning how to teach vocabulary through different techniques. Most teachers do not have adequate knowledge on vocabulary teaching techniques. Besides, lack of sufficient teaching materials indirectly or directly affected the teachers' attempt of practicing the techniques of vocabulary teaching in English classes.

The respondents suggested their own ideas how to enhance high school students' vocabulary knowledge or their vocabulary learning skills. In replying to this, most of the respondents reported that they needed training to be given to them on how they practically use the techniques to teach vocabulary. In general, it seems that many of the barriers to practice vocabulary teaching techniques may be reduced if the teachers get adequate training on how they practically practice vocabulary teaching through different techniques and have got sufficient teaching materials on vocabulary teaching strategies.

\subsection{Students' Responses to Items Related to the Practices of their Teachers' Strategies of Vocabulary Teaching}

Table 3.2.1: Frequency, percentage and mean of responses to items related to classroom practices of their teachers' vocabulary teaching strategies

\begin{tabular}{|c|c|c|c|c|c|c|c|c|c|}
\hline \multirow[t]{2}{*}{ Item } & \multirow{2}{*}{\multicolumn{2}{|c|}{ Statements }} & \multicolumn{5}{|c|}{ Responses } & \multirow[t]{2}{*}{ Total } & \multirow[t]{2}{*}{ Mean } \\
\hline & & & 5 & 4 & 3 & 2 & 1 & & \\
\hline \multirow{2}{*}{1} & \multirow{2}{*}{$\begin{array}{l}\text { How often does your teacher use definition to explain the } \\
\text { meaning of words during his/her vocabulary teaching? }\end{array}$} & & 51 & 34 & 11 & 0 & 0 & 96 & \multirow{2}{*}{-4.42} \\
\hline & & $\%$ & 53.1 & 35.4 & 11.5 & 0 & 0 & 100 & \\
\hline \multirow{2}{*}{2} & \multirow{2}{*}{$\begin{array}{l}\text { How often does your teacher teach you words that always } \\
\text { go together with the word that he/she is teaching? }\end{array}$} & $\mathrm{F}$ & 0 & 0 & 0 & 61 & 35 & 96 & \multirow{2}{*}{-1.64} \\
\hline & & $\%$ & 0 & 0 & 0 & 63.5 & 36.5 & 100 & \\
\hline \multirow[b]{2}{*}{3} & \multirow{2}{*}{$\begin{array}{l}\text { When the teacher teaches a word, how often does he/she } \\
\text { give you other words that have the same meaning with } \\
\text { the word he/she is teaching? }\end{array}$} & $\mathrm{F}$ & 48 & 39 & 9 & 0 & 0 & 96 & \multirow[b]{2}{*}{4.41} \\
\hline & & $\%$ & 50.0 & 40.6 & 9.4 & 0 & 0 & 100 & \\
\hline \multirow{2}{*}{4} & How often does your teacher explain the meaning of & $\mathrm{F}$ & 47 & 44 & 5 & 0 & 0 & 96 & \multirow{2}{*}{4.44} \\
\hline & words in relation to other words with opposite meaning? & $\%$ & 48.9 & 45.8 & 5.2 & 0 & 0 & 100 & \\
\hline \multirow{2}{*}{5} & How often does your teacher teach you by forming & $\mathrm{F}$ & 0 & 1 & 5 & 41 & 49 & 96 & \multirow{2}{*}{1.56} \\
\hline & vocabulary network? & $\%$ & 0 & 1.0 & 5.2 & 42.7 & 51.0 & 100 & \\
\hline \multirow{2}{*}{6} & \multirow{2}{*}{$\begin{array}{l}\text { How often does your teacher use pictures/diagrams to } \\
\text { teach vocabulary? }\end{array}$} & $\mathrm{F}$ & 0 & 0 & 1 & 42 & 53 & 96 & \multirow{2}{*}{-1.50} \\
\hline & & $\%$ & 0 & 0 & 1.0 & 43.8 & 55.2 & 100 & \\
\hline \multicolumn{9}{|c|}{ Mean } & 2.99 \\
\hline
\end{tabular}

Key: $\mathbf{5}=$ Always, $\mathbf{4}=$ Usually, $\mathbf{3}=$ Sometimes, $\mathbf{2}=$ Rarely, $\mathbf{1}=$ Never, $\mathbf{F}=$ Frequency, $\mathbf{0}=$ =Percent

As disclosed in the above table (see item number 1), 53\% of the students replied that their teacher always used definition to convey the meaning of new words during their vocabulary learning. The other $35 \%$ of the students responded that their teachers usually used definition in their vocabulary teaching. $12 \%$ of them answered that definition was rarely used in their actual vocabulary learning. As regards to item number $2,64 \%$ of the participants reported that collocation was rarely used in their vocabulary learning. But, $37 \%$ of the students replied that they never learnt vocabulary through collocation.

The classroom observation also showed that all the observed teachers used definition in their classroom teaching. According to McCarthy (1990), vocabulary instruction solely based on definition may help students acquire the meaning hardly enable them to use the word item in the real communication. An integration of collocation to definition provides prime opportunity of using the target vocabulary with other words in a harmonious relation and enables learners to attain effective communication in writing and speaking. Therefore, its absence in vocabulary teaching can be one of the sources of learners' limitations of using English for communication.

In reply to item $3,50 \%$ of the students reported that their teacher always used synonyms in the actual classroom. $41 \%$ and $9 \%$ of them responded that their teachers usually and sometimes used synonyms in their vocabulary learning, respectively. As regards to item number 4, 49\% of the respondents replied that their teachers used antonyms in their vocabulary learning. And also $46 \%$ of the students responded that their teachers usually practiced the meaning of new words in relation to other words with opposite meaning. The other $5 \%$ of the students replied that their teacher used it. Synonyms and antonyms emerged to be one of the most frequently used techniques. This is from the fact that teachers, students and textbook writers are traditionally fond of demonstrating new vocabulary items in terms of other words with the same meaning. The researcher observed the practice of antonyms and synonyms in all the four sessions of observations. However, it was observed that the teacher constructed a table of three columns on the blackboard where ten words were given in the first column and students were asked to provide synonyms and antonyms in the second and third columns, respectively. This sort of 
vocabulary presentation is believed to promote learners' memory of words after learning has already occurred which in turn improves the pace of vocabulary acquisition. Similar conclusion was arrived during observation in that teachers seemed to be keen on synonyms and antonyms as they often insist on getting students list down as many synonyms as possible for a word being taught.

Concerning item number $5,1 \%$ of the participants replied that vocabulary network was usually used by their teachers in their vocabulary learning. $5 \%$ of them answered that they were sometimes using it. The other $43 \%$ of the students replied that their teacher rarely used vocabulary network system in their learning. However, $51 \%$ of the students responded that their teacher never taught them using vocabulary network or word association. Schmitt (2000) argues that vocabulary items do not exist in the learners' mind as isolated entities, but in the form of association or vocabulary network where an attempt to recall one word item immediately prompts the retrieval of other related words. Class observation also showed that vocabulary network or word association was totally a neglected technique of vocabulary instruction.

All techniques of vocabulary instruction may not be equally useful for different types of words. Certain words can be better conveyed through verbal techniques and some others may require visual displays. In relation to this, there was a concern to know whether pictures /diagrams could be used by their teacher. $1 \%$ of the respondents answered that their teachers sometimes used pictures and diagrams in their vocabulary learning. The other $44 \%$ of them replied their teachers rarely practiced pictures or diagrams in their vocabulary lessons. However, $55 \%$ of the students reported that their teacher never taught them through pictures or diagrams. Pictures/diagrams were not employed during classroom observation. But, replies of the students' interview pointed out that pictures/diagrams were suggested in the text book. When this is explained in terms of mean, the mean value of the responses for these items is 2.99 which indicate low practice of vocabulary teaching techniques in the classroom.

Table 3.2.2: Frequency, percentage and mean of responses to items related to classroom practices of their teachers' vocabulary teaching strategies

\begin{tabular}{|c|c|c|c|c|c|c|c|c|c|}
\hline \multirow[t]{2}{*}{ Item } & \multirow{2}{*}{\multicolumn{2}{|c|}{ Statements }} & \multicolumn{5}{|c|}{ Responses } & \multirow[t]{2}{*}{ Total } & \multirow[t]{2}{*}{ Mean } \\
\hline & & & & \multirow{2}{*}{ 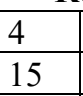 } & & \multirow{2}{*}{\begin{tabular}{|l|l|l}
2 \\
21 \\
\end{tabular}} & \multirow{2}{*}{\begin{tabular}{|l|l|l}
1 \\
17 \\
\end{tabular}} & & \\
\hline \multirow{2}{*}{7} & \multirow{2}{*}{$\begin{array}{l}\text { How often does your teacher use reading texts to teach new } \\
\text { words? }\end{array}$} & $\mathrm{F}$ & & & & & & 96 & \multirow{2}{*}{4.41} \\
\hline & & $\%$ & 2.1 & 15.6 & 42.7 & 21.9 & 17.7 & 100 & \\
\hline \multirow[b]{2}{*}{8} & \multirow{2}{*}{$\begin{array}{l}\text { In using reading texts for vocabulary learning, how often } \\
\text { does your teacher help you by indicating useful strategies } \\
\text { and specific clues to guess the meaning of words from } \\
\text { context? }\end{array}$} & $\mathrm{F}$ & 3 & 13 & 39 & 19 & 22 & 96 & \multirow[b]{2}{*}{4.18} \\
\hline & & $\%$ & 3.1 & 13.5 & 40.6 & 19.8 & 22.9 & 100 & \\
\hline \multirow[b]{2}{*}{9} & \multirow{2}{*}{$\begin{array}{l}\text { How often does your teacher connect the word to many other } \\
\text { words which have meaning relationship by establishing a } \\
\text { kind of network system (word web, word map, mind map, } \\
\text { word association)? }\end{array}$} & $\mathrm{F}$ & 1 & 1 & 2 & 39 & 53 & 96 & \multirow[b]{2}{*}{1.82} \\
\hline & & $\%$ & 1.0 & 1.0 & 2.1 & 40.6 & 55.2 & 100 & \\
\hline \multirow{2}{*}{10} & \multirow{2}{*}{$\begin{array}{l}\text { How often do you use different techniques of learning } \\
\text { vocabulary according to their suitability? }\end{array}$} & $\mathrm{F}$ & 1 & 3 & 7 & 36 & 49 & 96 & \multirow{2}{*}{4.42} \\
\hline & & $\%$ & 1.0 & 3.1 & 7.3 & 37.5 & 51.0 & 100 & \\
\hline \multirow[b]{2}{*}{11} & \multirow{2}{*}{$\begin{array}{l}\text { After learning words, how often does your teacher request } \\
\text { you to use the words when you are speaking and writing in } \\
\text { the class? }\end{array}$} & $\mathrm{F}$ & 1 & 1 & 3 & 33 & 58 & 96 & \multirow[b]{2}{*}{3.91} \\
\hline & & $\%$ & 1.0 & 1.0 & 3.1 & 34.4 & 60.4 & 100 & \\
\hline \multicolumn{3}{|c|}{ rand Mean } & & & & & & & 3. \\
\hline
\end{tabular}

Key: $\mathbf{5}=$ Always, $\mathbf{4}=$ Usually, $\mathbf{3}=$ Sometimes, $\mathbf{2}=$ Rarely, $\mathbf{1}=$ Never, $\mathbf{F}=$ Frequency, $\mathbf{\%}=$ Percent

As can be seen from the table above (see item number 7), 2\% of the respondents replied that their teacher always used reading texts to teach new vocabulary items. $16 \%$ of the students responded that their teachers usually practiced in the actual classroom. Besides, $43 \%$ of students reported that their teacher sometimes taught them through reading texts. $23 \%$ and $18 \%$ of them replied that their teachers rarely and never employed reading texts in their vocabulary learning, respectively. Teaching vocabulary through context was occasionally employed during classroom observation.

As regards to item number $8,3 \%$ and $14 \%$ of the students responded that their teacher always and usually taught them by indicating useful strategies and specific clues to guess the meaning of new words from context, respectively. Most of the students (41\%) replied that their teacher used contexts or contextualization their vocabulary learning. $20 \%$ of them answered that it was rarely practiced. $23 \%$ of them replied that their teacher never used contextualization in their vocabulary learning.

Item number 9 disclosed that $1 \%$ of the students responded that their teachers always taught them through meaning relationship by establishing a kind of network system such as word web, word map, mind map and word association. The other $1 \%$ of them reported that their teachers usually used it. Their teacher sometimes, $2 \%$, used a kind of network system in vocabulary teaching and learning. $41 \%$ of the respondents replied that their teacher rarely practiced vocabulary network system in the actual classroom. On the other hand, most of $(55 \%)$ the 
respondents reported that their teacher never used vocabulary network system as a technique of vocabulary teaching.

In learning vocabulary, different techniques are encouraged to be used according to their suitability. But, 1\% and $3 \%$ of the students responded that they always and usually used different techniques of vocabulary learning according to their suitability, respectively (see item number 10). $7 \%$ of them sometimes used them. On the other hand, $38 \%$ the respondents reported that they rarely used different vocabulary teaching techniques according to their suitability. $51 \%$ of them never practiced the techniques.

As regards to item number $11,1 \%$ of the students replied that, after learning vocabulary, their teachers always asked them to practice the words when they are speaking in the class and outside the class. The other $1 \%$ and $3 \%$ of them reported that their teacher usually and sometimes used it, respectively. 34\% of the respondents answered that their teacher rarely asked them to do it. But, $60 \%$ of the participants responded that their teacher always asked them to practice the words when they are speaking in the class and outside the class.

In general, the data from students' response clearly showed that definition, antonyms and synonyms were frequently employed by their teachers. Contextualization was occasionally used. However, collocation, vocabulary network, word association, pictures and diagrams were totally ignored though they were suggested in the students textbook. When this is explained in terms of mean, the mean value of the responses for these items is 3.75 which indicate moderate practice of vocabulary teaching techniques in the classroom.

\section{Conclusions and Recommendations}

This chapter presents the conclusions and recommendations of the results of the study.

\subsection{Conclusions}

Based on the analyses and discussions made in the study, the following conclusions are drawn.

\# The overall findings of the study disclosed that the teachers did not employ various vocabulary teaching techniques during their vocabulary instruction. Vocabulary teaching was found to be ineffective in the school. The students were poor in their vocabulary.

* The teachers most frequently used techniques of vocabulary teaching such as definition, antonym and synonym. Using only these techniques is not good for the students' vocabulary improvement.

* Teachers sometimes used contextualization as a method of vocabulary teaching to help students use words in a variety of circumstances.

* Reading is considered as the most effective approach to vocabulary presentation. It was found that teaching vocabulary through reading was rarely used.

* It was found that teachers rarely used collocation as a method of vocabulary teaching in their actual classroom.

\# It was found that techniques of vocabulary teaching such as vocabulary network (word association, word map, mind map, etc.), pictures, diagrams, etc. were neglected in the teachers' vocabulary presentations.

\subsection{Recommendations}

Based upon the findings of the study and the conclusions drawn, the following recommendations are made.

* Teachers should develop favorable tendency to the primacy of using different vocabulary teaching techniques in the process of teaching and learning vocabulary so that they will be able to consider the techniques as the major component in their vocabulary lessons. And teachers are encouraged to use the techniques according to their suitability.

* Techniques of vocabulary instruction such as collocation, contextualization, homonym, hyponym, vocabulary network, pictures and diagrams need to be used as often as definition, synonym and antonym.

* The students need to be aware of the merits of vocabulary learning through various techniques so that they become motivated and thereby actively play their roles in using the techniques in their vocabulary learning.

* Instructional and reference materials on vocabulary instruction are vital factors for the practice and implementation of vocabulary teaching techniques. And fulfilling the necessary vocabulary teaching materials should be the concern of the school administration and other stake holders.

* In fact teachers are principal change agents, considerable effort should be made to change them first. Teachers should be updated with recent changes or innovations. This could be achieved through continuous training such as seminars, workshops and in-service training programs.

\section{Conflicts of interest}

The author has not declared any conflict of interests.

\section{References}

Abebe Gebre Tsadik. (1997). "Strategies of Vocabulary Learning of AAU Freshmen Learning English as a 
Second/Foreign Language" (Unpublished PhD Dissertation). Addis Ababa: AAU.

Alemu Hailu (1994). "High School Teachers' Attitude towards an Awareness Raising Approach to Vocabulary Teaching." Addis Ababa: Addis Ababa University.

Al-knfasm, A. (1988). "Vocabulary-building Programme is a Necessary not a Luxury": English Teaching Forum. Washington D.C. $26(2)$.

Allen, V. F. (1983). Techniques in Teaching Vocabulary. Oxford: Oxford University Press.

Bailey, K. D. (1994). Methods of Social Research. $\left(4^{\text {th }}\right.$ ed). New York: The Free Press. https"//www.vcm.org.

Carter, R. and McCarthy, M. (1988). Developments in the Teaching of Vocabulary: Teaching English as a Second or Foreign Language. London: Longman. (1991). Vocabulary and Language Teaching. London: Longman.

Coady, J. \&. Huckin, Th. (1997). Second Language Vocabulary Acquisition. Cambridge: CUP. . (2000). Second Language Vocabulary Acquisition: Applied Linguistics. Cambridge: CUP.

Cohen, A.D. \& Macaro, E. (2007). Language Learning Strategies: Oxford: OUP.

Dessie Berhane. (1988). “An Evaluation of the Effectiveness of Modern Vocabulary Teaching Methods and the Extent to which these are Implemented in the Freshman English Course" (MA. Thesis, unpublished). Addis Ababa: Addis Ababa University.

Diribsa Dufera, et al. (1999). "Principles of Curriculum Inquiry. Distance Education Material for In- service Trainee" (Unpublished Material). Addis Ababa: Addis Ababa University.

Harmer, J. (1991). The Practice of English Language Teaching. London: Longman.

Hatch, E., \& Brown, C. (1995). Vocabulary, Semantics, and Language Education. Cambridge: Cambridge University Press

McCarthy, M (1990). Vocabulary. Oxford: Oxford University Press.

Miller, G. A. (2000). Human Vocabulary as Display. https:/wikipedia.org/wiki/modiglian.

Nation, P. (1990). Teaching and Learning Vocabulary. Boston: Heinle.

. (2001). Learning Vocabulary in another Language. Cambridge: Cambridge University Press.

. (2005). "Teaching Vocabulary in Difficult Circumstances": ELT Journal. 30/1 (1975): 21-24.

Nattinger, J. R. (1988). "Trends in Vocabulary Teaching.” In R. Carter \& M. McCarty (Eds.). Vocabulary and Language Teaching (1st ed.). New York: Longman.

Richards J. C. \& Renandya, W. A. (2002). Methodology in Language Teaching: An Anthology of Current Practice. Cambridge: Cambridge University Press.

Sara Tadesse. (1989). “The Effectiveness of Vocabulary Teaching in some Secondary Schools”. Addis Ababa: Addis Ababa University Press.

Schmitt, N. (2000). Vocabulary in Language Teaching. Cambridge: Cambridge University press. . (2008). Instructed Second Language Vocabulary Learning. www.hetutors.com.

Stahl, S. (1999). Vocabulary Development. Cambridge, MA: Brookline Books.

Taylor, L. (1990). Teaching and Learning Vocabulary. Herefordshire: Prentice Hall.

(1991). A Systematic and Principled Approach to Vocabulary Teaching. https://soai.repo.nii.ac.Jp/index.php.

Tesfaye Mahazentu (1990). “An Evaluation of the Effectiveness of Current Techniques in Vocabulary Teaching to Grade four students". (Unpublished, MA Thesis), Addis Ababa: AAU. 